\title{
Pensando a diferença na escola - possibilidades de um currículo multicultural
}

\author{
Michele Barcelos Doebber
}

Resumo: O presente artigo trata do desafio de pensar uma proposta pedagógica para crianças, por meio de um projeto de abordagem multiculturalista, que valorize as diferenças e problematize as construções naturalizadas em suas vivências cotidianas. Apresenta o projeto "Descobrindo a Beleza das Nossas Origens", desenvolvido com o objetivo de resgatar as origens dos alunos e as culturas dos povos dos quais descendem, de modo a permitir que as crianças ressignifiquem a sua história e o seu pertencimento etnicorracial a partir do contato com outros discursos e representações, principalmente dos povos indígenas e africanos. Com o desenvolvimento do projeto pode-se perceber que foi possível operar com alguns deslocamentos nas concepçôes dos/ as alunos/as, assim como gerou maior entendimento e respeito na relação entre eles/as.

Palavras-chave: Currículo multicultural, Diferenças, Identidade.

\begin{abstract}
This article deals with the challenge of thinking a pedagogical proposal to children through a project with multicultural approach that values differences and discusses the naturalized constructions in their everyday experiences. Presents the project "Discovering the Beauty of Our Origins", developed with the objective of rescuing the students origins and the cultures of the people they descend from, in order to allow children to reframe its history and its ethnic-racial belonging from contact with other

* Pedagoga e Técnica em Assuntos Educacionais da Universidade Federal do Rio Grande do Sul. Mestranda em Educação - Programa de Pós-Graduação em Educação/ UFRGS. E-mail: micheledoebber@yahoo.com.br
\end{abstract}


speeches and representations, especially of indigenous nations and africans. With the development of the project it was perceived that some shifts in students conceptions can be worked, and also generated a greater understanding and respect in the relationship between them.

Keywords: Multicultural curriculum, Differences, Identity.

[...] os sentidos diversos do multiculturalismo precisam ser analisados, de forma que práticas curriculares não acabem por perpetuar a construção das diferenças e dos preconceitos que tanto desejam combater (CANEN, 2002, p.181).

O currículo está no centro de toda atividade educacional. É nele que se corporificam as concepções de educação, os objetivos do ensino, o conjunto de valores, os conhecimentos e práticas culturais tidos como válidos de serem transmitidos por uma instituição escolar.

Segundo as teorizações contemporâneas, um currículo será sempre uma seleção de saberes que nunca é desinteressada, mas sempre deseja algo, quer alguma coisa. Sendo assim, podemos considerar o currículo, além de produzido, também como produtor, que, como qualquer outro artefato cultural e como qualquer outra prática cultural, nos constitui como sujeitos particulares, específicos. Desse modo, ao selecionar os conteúdos e as temáticas que serão desenvolvidos, o discurso do currículo legitima ou deslegitima, inclui ou exclui. Ao mesmo tempo em que traz à luz alguns saberes, outros sempre são deixados de lado, à margem. Que conhecimentos estão sendo eleitos para o estudo com os nossos grupos de alunos?

Em seus escritos, Silva (1995) destaca que o currículo deve ser entendido como uma produção da cultura, tendo um caráter histórico e político. A partir disso, nos provoca a pensar sobre quais identidades sociais estão sendo privilegiadas nos currículos escolares. $\mathrm{O}$ autor propõe que o currículo se torne um território contestado, a partir do que os significados devem ser questionados, disputados e redefinidos. 
Santomé (1995) comenta que, quando analisados os conteúdos que são desenvolvidos na maioria das instituiçõos escolares, é "arrasadora a presença das culturas que podemos chamar de hegemônicas” (p. 161). As culturas dos grupos sociais marginalizados costumam ser negadas e silenciadas ou ainda tratadas de forma estereotipada, anulando suas possibilidades de reação. Nesse sentido, o multiculturalismo se coloca como uma alternativa que

busca respostas plurais para incorporar a diversidade cultural e o desafio a preconceitos, nos diversos campos da vida social [...]. No campo do currículo, desconfia de discursos que se apresentam como meramente técnicos, buscando perceber neles vozes autorizadas e vozes silenciadas. Verifica em que medida esses discursos constroem imagens estereotipadas do negro, da mulher, do deficiente físico, daqueles grupos portadores de culturas, religiões e linguagens diferentes das dominantes (CANEN, 2002, p. 178-179).

Através das práticas educacionais, das vivências na família, na rua, com os pares e nos demais espaços sociais, na interação com a mídia e com as tecnologias da informação, as crianças constroem seus modos de ser e estar no mundo e de relacionar-se com ele. Pouco a pouco se tornam conscientes de sua existência, sentindo-se membro de uma comunidade a partir da identificação e diferenciação com os demais.

É importante registrar que vivemos e educamos nossos/as alunos/as num tempo contraditório, e é nesse tempo que somos chamadas/os a atuar, a fazer escolhas, a selecionar textos e conteúdos para nossas aulas. É nesse contexto que precisamos, cada vez mais, questionar o que nos parece óbvio, o que parece dado como natural.

No intuito de desestabilizar, provocar, desacomodar as crianças em suas concepções já cristalizadas a respeito dos povos dos quais descendem, problematizando os discursos produzidos e proporcionar outras possibilidades de identificação foi desenvolvido o trabalho que exponho a seguir. ${ }^{1}$

1 O presente trabalho consiste no relato de uma prática pedagógica desenvolvida no período de estágio curricular do curso de Pedagogia, sob orientação da $\operatorname{Prof}^{\mathrm{a}} \operatorname{Dr}^{\mathrm{a}}$ Maria Luisa Merino Xavier, com uma turma de $3^{\mathrm{a}}$ série do Ensino Fundamental, realizada no Colégio de Aplicação da UFRGS, no ano de 2006. 
A proposta de trabalho consistiu no projeto "Descobrindo a beleza das nossas origens", inserido no projeto de extensão já existente na escola intitulado "Nossas Raízes"l.

Percebendo que na turma havia uma grande diversidade de cores, raças, culturas, crenças, crianças provenientes de situações econômicas as mais variadas, e que nem sempre essas diferenças eram vistas entre elas de forma positiva, foi desenvolvido tal projeto. Senti-me provocada pelas ideias de Silva e Grupioni (1995), os quais destacam que um dos maiores desafios que se colocam à escola é de como pensar a diferença.

Diferença entre povos, culturas, tipos físicos, classes sociais: estará fadada a ser eternamente compreendida e vivida como desigualdade? [...] Respeito à diferença, saber conviver com os que não são exatamente como eu sou ou como eu gostaria que eles fossem e fazer das diferenças um trunfo, explorá-las em sua riqueza, possibilitar a troca, o aprendizado recíproco $[\ldots]$ (p. 17-18).

Com o desenvolvimento de atividades de diferentes tipos, das quais destaco algumas para comentar no decorrer do texto, procurei desenvolver um trabalho de resgate da identidade, da história e das origens dos alunos. Tinha como objetivos que as crianças fossem capazes de perceber a diversidade de origens na turma, bem como a diversidade étnica e cultural; construir relações de respeito com os diferentes povos, culturas e etnias e relacionar-se com o outro de forma mais humana, fraterna, cuidadosa e afetiva. Dessa forma, pretendi proporcionar aprendizados que integrassem as diversas áreas do conhecimento, partindo de temáticas significativas na vida das crianças.

2 O Projeto Nossas Raizes foi criado a partir de um processo que teve início por volta de 1993. Desdobrou-se posteriormente no Projeto de Pesquisa Heterogeneidade, orientado pela Prof ${ }^{a}$ Marlene Brugalli, e nos projetos de extensão Nossas Origens - coordenado pela Prof ${ }^{\mathrm{a}}$ Marilene Leal Paré - e Construindo Vínculos - coordenado pela Prof ${ }^{\mathrm{a}}$ Danusa Mansur Lopes. No ano de 2006, o Projeto Nossas Raizes era coordenado pela Prof ${ }^{a}$ Danusa Mansur Lopes e composto pela equipe de professores do Projeto UNIALFAS: Débora Ferrari Martinez, Aline Rocha Scislewski, Valéria Raimundo, Cíntia Bauer, Lígia Schukster, Fernanda Vebber, Ignez Borgese, Janaína Bopp, Leandro Miguens, Martha Guterres, Mônica Eztrázulas, Silvana Silva, Maíra Barberena Mello, Maria Helena de Lima e Débora Markus Martins (bolsista de extensão). 


\section{A Pedagogia de Projetos e o currículo multicultural - alternativas para movimentar as diferenças}

A escolha por realizar um trabalho baseado na Pedagogia de Projetos foi por acreditar que através desse tipo de proposta é possível integrar as áreas de conhecimento, interligando temáticas e respeitando os interesses e necessidades dos estudantes. Para o estudo de problemas contemporâneos significativos para o grupo de alunos, toma-se como ponto de partida suas concepções, hipóteses e conhecimentos, tendo em vista que "a aprendizagem se baseia em sua significatividade” (HERNÁNDEZ, 1998, p. 64).

A base deste trabalho é a troca de saberes e o diálogo. Para que tal pressuposto se efetivasse, o trabalho foi organizado por grupos. Segundo Freire (1997, p. 17), é no grupo que cada participante exercita "sua fala, sua opinião, seu silêncio, defendendo seus pontos de vista". É no grupo que cada criança se descobre como diferente, no contato com o outro, construindo sua identidade. Através do espaço de discussão, no qual a criança tem liberdade para o questionamento, para a dúvida, a crítica, a formação da própria opinião, a autonomia, é que ela se constrói enquanto indivíduo, assumindo-se enquanto sujeito. Desse modo, buscou-se trabalhar com a necessidade de desenvolver argumentaçõoes em relação às posições sobre os fatos e discursos; promover uma desnaturalização das relações poder/saber, incitando as crianças perceberem que existem outras possibilidades de se pensar as relações e representações sociais, exercitando a dúvida e a desconfiança frente aos conhecimentos cristalizados e/ou mesmo dos significados considerados transcendentais; estabelecer, com essa ampliação de conhecimento, uma nova relação com a cultura e a sociedade em que esses estudantes vivem.

Vejo como importante trazer conteúdos do meio social e cultural nos quais os alunos estão inseridos, proporcionando que estes se sintam valorizados e respeitados nas suas diferenças. 
Nesse sentido, Hickmann (2002, p. 15), destaca a necessidade de se elaborar um planejamento pedagógico com propostas:

que transitem entre as identidades, enquanto identificação e reconhecimento de cada um, através da retomada de sua história pessoal, como também revisitar os outros, deixando-se capturar pelo estranhamento de outras culturas para poder descobrir-se na sua. Ou seja, a identidade e a diferença caminham juntas. É preciso que eu me veja num outro, estranho a mim, para poder redescobrir-me.

O planejamento didático-pedagógico referente ao projeto "Descobrindo a beleza das nossas origens" foi composto por quatro temáticas principais, sendo elas: Trabalhando a partir do próprio nome, Refletindo sobre a própria vida, Pesquisando as nossas origens e Valorizando a beleza do nosso corpo.

Dentre as várias atividades realizadas, destaco a seguir três momentos que considero mais significativos referentes ao projeto desenvolvido: Povos indígenas - o que sabemos sobre essa nossa origem; Refletindo sobre a própria vida, produzindo cartas e Resgatando as origens a partir dos sobrenomes.

Tecerei comentários sobre cada um deles, contando os principais deslocamentos e aprendizados que proporcionaram à turma e a mim enquanto professora.

\section{Povos indígenas - o que sabemos sobre essa nossa origem?}

“[...] eles não usam roupas, usam folhas de bananeira, fazem bló, bló, bló, gritam. Usam arco e flecha para caçar. ${ }^{3}$

Há estudos - dentre eles destaco Bonin (2007) - que mostram o quanto a temática dos povos indígenas é trabalhada nas escolas de forma estereotipada, genérica, tipificada, exótica, cristalizada, principalmente quando vemos esse assunto ser abordado somente no "dia do índio". Santomé (1995) chama

${ }^{3}$ Falas das crianças em relação aos povos indígenas. 
a atenção para a importância de tratarmos as culturas negadas nos currículos mais seriamente e de forma contínua, não caindo em propostas do tipo "currículos turísticos, ou seja, em unidades isoladas, através das quais, esporadicamente, se pretende estudar a diversidade cultural” (p. 173).

Buscando um distanciamento dessa ideia e com a intenção de ampliar a discussão para além de um único dia, problematizando algumas concepções já cristalizadas sobre os povos indígenas, é que foi desenvolvida uma série de atividades as quais relato a seguir.

Solicitei que fosse respondida a seguinte pergunta: $O$ que sabemos sobre os indios?

As respostas das crianças para tal questão foram as seguintes: "pintavam-se com tintas extraídas das folhas"; "alguns moravam em ocas, em reservas indígenas"; "alguns são canibais"; "caçam animais"; "usam enfeites no corpo"; "usam machados, arco e flechas, lança"; "nunca vi um índio realmente"; "já vi em foto"; "meu avô é índio"; "usam canoa"; "temos dúvida sobre como se vestem".

Só esse primeiro momento já gerou grande discussão no grupo, como, por exemplo, sobre as vestimentas dos índios. Algumas crianças diziam que eles não se vestiam; outras defendiam que se vestiam com folhas, ou com roupas como as nossas.

Podemos observar nas falas acima que os povos indígenas são pouco conhecidos e são muitos os estereótipos veiculados a eles. O índio é descrito como se estivesse parado no tempo, como se fosse aquele índio de 500 anos atrás que vivia na selva, pescava, caçava, usava arco e flecha e andava quase sempre nu. Também como aquele que está distante, que eu desconheço, com o qual não tenho contato, o diferente. Somente em uma fala percebi maior proximidade com a temática, quando uma das crianças comentou que seu avô era índio. Praticamente, não foi feita nenhuma referência aos índios urbanos, que hoje vivem nas grandes cidades, vivendo e sobrevivendo de diversas formas.

Depois dessa primeira "chuva" de ideias, apresentei algumas palavras ou expressões escritas em papéis coloridos. Chamei-as de 
palavras-âncora, para instigar a discussão de modo a aprofundar alguns temas. As expressões foram as seguintes: povos indígenas, preconceito, outros modos de viver, riqueza cultural, diferenças, respeito. Colei-as no quadro e pedi que as crianças relacionassem o tema que estávamos discutindo com aquelas expressões. Esse momento teve grande participação da turma e foi produtivo para que, na discussão com os colegas e a partir das minhas intervenções, as crianças pudessem fazer alguns deslocamentos colocando em xeque conhecimentos que possuíam até então.

Ressalto a importância do papel de mediador do/a professor/a durante todo o debate, trazendo novos questionamentos e conhecimentos, assim como problematizando questões que possivelmente surjam ao longo do diálogo.

Em outra aula, retomamos o estudo do tema com a leitura e interpretação do texto "É índio ou não é índio?”. O mesmo é narrado por Daniel Munduruku, um índio que mora na cidade de São Paulo, e conta uma situação que ele mesmo vivenciou, em que duas senhoras discutem, dentro do metrô da cidade, se ele é índio ou não. Para isso, as senhoras utilizam-se, principalmente, de suas características físicas nas argumentações.

Após a leitura do referido texto, pude questionar o posicionamento/opinião das crianças a respeito do personagem. Ele pode ser índio se veste roupas? Existem índios na cidade? Por que uma das senhoras achou que ele não era índio? O personagem gostava de ser índio? Essa discussão foi muito rica, pois as crianças ficaram instigadas e provocadas a pensar. Aos poucos entravam em choque com a ideia inicial que pareciam ter, mostrando certo estranhamento às novas informações e conhecimentos que estavam construindo. Será que um índio poderia estar na cidade, totalmente vestido como nós e andando de metrô?

Muitas vezes, quando o índio é deslocado do seu lugar tido como "natural", a mata, tem-se a ideia de que ele não é mais índio, de que perde a sua identidade indígena, de que deixa de ser um índio "verdadeiro", "puro". 
Ainda nesse mesmo dia, assistimos ao documentário "Povos indígenas - direito à diferença”. A seguir, destaco o comentário sobre o filme encontrado em um site da internet ${ }^{4}$ :

Aprender a conviver com o diferente é fundamental para que haja respeito e justiça entre os povos. Os povos indígenas têm esta visão. Veja o que diz a Núbia, do povo Tupinambá, BA: "Temos a esperança de viver livre como um povo, como nação. Isto é forte na gente. A gente trabalha, a gente vive, levanta, faz celebração, com este objetivo: de viver livre como um povo que tem sua história, sua religião; um povo que tem seu jeito de viver diferente. Não querendo ser um modelo para ninguém, mas pra viver como nós somos, não como os outros querem que a gente seja, mas como nós realmente somos. A gente ainda está resistindo, as aldeias estão ressurgindo por conta desse sonho e a esperança de viver enquanto povo, sem discriminação, sem zombaria, sem verem a gente como coisa do outro mundo".

O filme trata da situação em que vivem os povos indígenas no Brasil. A exploração feita pelos brancos desde a chegada dos portugueses, as formas de organização para a luta e resistência na busca pela garantia de direitos, as dificuldades encontradas atualmente, como a expropriação de suas terras e a pobreza crescente, são temas abordados no filme. Além disso, traz imagens de diversos povos indígenas, de diferentes regiões do Brasil, com culturas muito diferentes umas das outras, deixando claro que cada sociedade indígena tem sua própria identidade e que "cada um desses povos tem um modo próprio de ser e uma visão de mundo específica. A diversidade se manifesta nas tradições, nos cantos, nos mitos, na arte, na economia, na história e nas línguas (GRUPIONI, 2001, p. 9).

Durante o filme, fui comentando diversas passagens que considerei importantes e, ao final, fizemos um momento de conversa, quando as crianças apresentaram suas impressões e os questionamentos que haviam ficado após assistirem ao filme.

4 Disponível: http://www.mundojovem.pucrs.br/video-2002.php, pesquisa realizada em 20 de ago. 2009. 
Durante a discussão, foram levantadas questões sobre por que o índio Galdino foi queimado ${ }^{5}$, a situação de pobreza em que vivem muitos povos indígenas no Brasil hoje, como historicamente os povos indígenas foram massacrados e explorados, a organização e resistência dos mesmos na luta por seus direitos etc.

Para finalizar esse trabalho, realizei a leitura da apresentação do livro "Coisas de índio - versão infantil", de Daniel Munduruku. Nessa parte do livro, o autor fala sobre como se sente enquanto índio e como ele sonha que as pessoas passem a entender e respeitar os povos indígenas da maneira como eles são. Após, montamos um painel a partir da seguinte proposta: $\mathrm{O}$ que aprendemos/descobrimos sobre os povos indígenas? Abaixo apresento alguns registros das crianças sobre suas descobertas e aprendizados:

Eu aprendi no filme que os POVOS indígenas tinham muita PAZ, mas com a chegada dos brancos começou a briga e morreram MUITOS índios, ainda mais aquele índio que morreu queimado. $\mathrm{E}$ o que eu aprendi na aula é que eles eram escravos e existia o racismo com as duas raças [negros e índios].

Aprendi que eles são pobres e que os homens brancos poluíram o rio e os índios ficaram sem comer e todos eles foram fazer greve em Brasília e um índio morreu queimado pelos jovens e eles faziam coisas para eles e eles curavam as pessoas.

Aprendi que os índios também usam roupas, relógio, sapato e mais coisas... que os brancos poluem os lagos, mares e rios. E roubavam as plantas que eram remédio deles. Os índios vivem da natureza e os brancos pegaram e poluíram cada vez mais.

Eles andavam com palha na cintura, usam arco e flecha para caçar, tem umas características diferentes da nossa.

Aprendi que os índios não só moram na mata, também podem viver na cidade [...]. Que índios são que nem a gente e também que existem algumas pessoas racistas.

5 Galdino Jesus dos Santos era um índio Pataxó que foi assassinado por cinco jovens de classe média, em Brasília, no dia 20 de abril de 1997. Ver mais em: http://www. sindicato.com.br/artigos/cimi.htm. Pesquisa realizada em 22/09/2009. 
Foram escravizados há muitos anos pelo homem branco.

São gente igual a gente.

Baseada em Grupioni (2001, p.23), que diz que "somente na medida em que reconhecermos a diferença, seja em que grau for, como valor positivo, será possível atribuir aos índios um lugar efetivo e digno como cidadãos de um país, cuja plena cidadania só pode ser definida e construída por um viés plural", e que, além disso, "é preciso um novo olhar sobre aqueles que são diferentes de nós por partilhar de outras crenças, pertencer a outras classes sociais, ter raízes históricas distintas, por se guiar por suas lógicas e seus valores próprios", vejo o quanto é importante esse tipo de trabalho.

Todas as atividades e discussões realizadas e a observação dos resultados do trabalho nas aprendizagens das crianças me provocaram uma série de reflexôes. Percebi que, mesmo a temática tendo sido explorada em poucos momentos, algumas das crianças construíram aprendizados muito significativos em relação ao que diziam saber logo no início do estudo. Outras, porém, pareceram-me não terem sido tocadas pela temática, permanecendo com as mesmas concepções e hipóteses que já possuíam anteriormente. Isso nos mostra que é possível, a partir da intervenção pedagógica, provocar alguns deslocamentos. Porém, como todo processo educativo, exige tempo, retomadas constantes e não atinge todos da mesma forma.

\section{Refletindo sobre a própria vida, produzindo cartas}

Nós estamos eternamente contando histórias sobre nós mesmos (SCHAFER apud LOPES, 2002, p. 57).

As atividades relatadas a seguir tiveram como objetivo oferecer às crianças a oportunidade de refletirem sobre suas vidas, sobre suas experiências, enquanto sujeitos pertencentes a um meio e que se relacionam com diversos grupos sociais a todo o momento. 
Além disso, propiciaram também o autoconhecimento, o resgate da identidade e a possibilidade de autonarrarem-se através da escrita de uma carta. Esse tema torna-se relevante no momento em que nos damos conta de que "é na escola [...] que as crianças, em geral, se expõem, pela primeira vez, a significados que podem contestar ou confirmar quem elas são com base em como suas identidades foram construídas na família” (LOPES, 2002, p. 59).

Iniciamos o trabalho realizando pesquisas e atividades tais como escrita de autobiografia com colagem de fotos, pesquisa da história do próprio nome, confecção de autorretrato ${ }^{6}$, confecção de acróstico a partir do nome e pesquisa na internet sobre as origens dos nomes.

Após esse trabalho, sugeri uma atividade que foi chamada de "Como eu sou?". Propus às crianças que escrevessem sobre os seus corpos (como eram fisicamente), do que gostavam (de fazer, de vestir, de comer...), do que não gostavam, o que pensavam sobre suas famílias e quais eram seus sonhos para o futuro.

Segundo Sarup apud Lopes (2002, p. 64), "as narrativas são instrumentos que usamos para fazer sentido do mundo a nossa volta e, portanto, de quem somos neste mundo. $\mathrm{O}$ ato de contarmos e ouvirmos histórias tem um papel crucial na construção de nossas vidas e das vidas dos outros." Bruner apud Lopes (2002, p. 64), nesse mesmo sentido, afirma que "nos tornamos as autobiografias narrativas pelas quais contamos nossas vidas." E ainda Linde apud Lopes (2002, p. 64) aponta que "a narrativa é usada para criar [um] sentido interno de si-mesmo, e como um dos mais importantes recursos que usamos para transmitir e negociar este si-mesmo com os outros”.

Após esse momento em que as crianças tiveram que produzir narrativas sobre si mesmas, lancei a proposta de que iniciássemos um intercâmbio de cartas com crianças da terceira série de uma escola estadual de Porto Alegre. Esse trabalho teve como objetivo produzir textos numa situação real de interlocução em que as

6 A confecção de autorretrato foi motivada através da leitura do poema "Na minha pele”, de Sérgio Capparelli. 
crianças deviam escrever quem eram seus gostos e jeito de ser, e questionar o interlocutor sobre assuntos que fossem de seus interesses. As crianças aceitaram prontamente a ideia e iniciaram a escrita das cartas de forma entusiasmada. Ficaram tão animadas que sugeriram que combinássemos um encontro com a turma do outro colégio para se conhecerem.

Geraldi (1997, p. 121) comenta que "na escola não se produzem textos em que um sujeito diz sua palavra, mas simulase o uso da modalidade escrita, para que o aluno se exercite no uso da escrita, preparando-se para de fato usá-la no futuro. É a velha história da preparação para a vida, encarando-se o hoje como não-vida”. Para contrapor essa ideia, acredito e trabalho na perspectiva da Pedagogia de Projetos, considerando importante a situação de escrita em que as crianças escrevem porque tem o que dizer e para quem dizer.

Dessa forma, o trabalho com produção textual se torna algo "real", válido, contextualizado. Para Jolibert (1994, p.21), "a pedagogia de projetos permite viver numa escola alicerçada no real, aberta a múltiplas relaçôes com o exterior: nela a criança trabalha 'para valer' e dispõe dos meios para afirmar-se".

Lopes (2002, p. 64) conclui que "ao historiarmos a vida social para outro, estamos construindo nossas identidades sociais ao nos posicionarmos diante de nossos interlocutores e diante dos personagens que povoam as nossas narrativas." Sendo assim, penso que nessa situação as crianças puderam refletir, problematizar, questionar e afirmar suas identidades no momento em que tiveram que se posicionar em relação a um amigo ainda desconhecido.

E importante referir que aproveitei o trabalho com cartas para estudar essa tipologia textual, destacando sua estrutura, os elementos que a compóem e o preenchimento adequado de um envelope. 


\section{Resgatando as origens a partir dos sobrenomes}

Cada um traz um monte de origens. [...] Então quantas origens eu carrego dentro de mim? Quantas sementes?7

Este excerto é parte de um texto chamado "Você e sua história", texto este que deu início à discussão sobre as origens dos alunos da turma. A autora defende que cada pessoa carrega dentro de si um pouquinho de seus pais, avós, bisavós... e de suas origens. Trata principalmente da questão da mistura étnica e valoriza de forma especial a origem africana. Silva (2004, p. 102) destaca a relevância desse tipo de trabalho quando discute que

a questão da raça e da etnia não é simplesmente um "tema transversal": ela é uma questão central de conhecimento, poder e identidade. O conhecimento sobre raça e etnia incorporado no currículo não pode ser separado daquilo que as crianças e os jovens se tornarão como seres sociais.

Procurando incorporar essas questões no currículo e na vida das crianças, para que fizesse sentido para elas, parti para a realização de diversos trabalhos que as levassem à investigação/ pesquisa a respeito das suas origens. Motivadas a descobrirem de onde vieram, quais suas ascendências, conhecerem a respeito de suas histórias e de se colocarem no papel de historiadoras, as crianças montaram seu quadro de origens. Em conversa com os pais, avós, parentes, procuraram completar informações como o nome, local e data de seu nascimento, de seus pais e avós maternos e paternos. Com posse das informações obtidas nessa atividade, cada criança pôde montar sua árvore genealógica. Durante o desenvolvimento dessa atividade, bem como durante todo o desenrolar do projeto, as crianças participaram ativamente, dialogando e refletindo sobre curiosidades e informações importantes que haviam descoberto na conversa com seus familiares.

Excerto retirado do texto "Você e sua história" que faz parte do livro Histórias da Preta, de Heloisa Pires Lima, Companhia das Letrinhas. 
Uma aluna partilhou: "Profa, eu descobri o nome do meu pai". Fiquei sem palavras ao ver a alegria da menina e muito satisfeita ao perceber o quanto uma atividade simples como a realizada pode gerar aprendizados tão significativos na vida de algumas crianças, os quais eu não havia imaginado que poderia proporcionar.

Aproveitei também para questioná-las quanto aos meios que haviam utilizado para conseguir as informações necessárias, e as crianças relataram terem realizado conversas com os pais, avós, tios, além de telefonemas e pesquisas em documentos. Nesses momentos, também pude enfatizar a importância dos documentos e dos relatos orais para a construção da nossa história pessoal e da história da humanidade e também para valorizar as crianças enquanto pesquisadoras, detetives da própria história, verdadeiras historiadoras. Todas ficavam muito envaidecidas com esse tipo de caracterização.

Todo esse trabalho teve como objetivo permitir que as crianças pudessem pesquisar sobre seus antepassados e suas origens, resgatar as histórias familiares, trabalhar com o conceito de identidade, valorizar a memória e a história transmitida oralmente e também perceber a importância dos documentos e do relato oral na construção da história. Como salienta Callai (1995, p.37), as Séries Iniciais do Ensino Fundamental

devem levar o aluno a pensar historicamente, isto é, na perspectiva do decurso do tempo, sendo aí fundamental o estudo da história da família e da história de vida do aluno, identificando-se, em decorrência, certas regularidades que remetem à organização mais ampla da sociedade e percebendo-se as mudanças culturais.

Na mesma perspectiva dessa autora, Hickmann (2002, p. 37) destaca a importância do trabalho na área das Ciências Sociais. Dentre os objetivos norteadores que ela apresenta estão contribuir para o processo de construção da autonomia; da identidade cultural, social, histórica; da subjetividade e cidadania, através da leitura de seus jeitos de ser, viver, relacionar-se e do resgate da memória pessoal e coletiva, que expressa um universo de valores morais e éticos, crenças, atitudes, normas e regras de convívio do seu contexto social. 
Também, diz a mesma autora, tais propostas conseguem "provocar o desejo de conhecer outras culturas, povos e países, tanto atuais como de outros tempos e espaços, sensibilizando-as para uma aproximação, para o diálogo e acolhimento ao 'outro"' (p. 11). Destaquei essas afirmações, pois penso que vão ao encontro das propostas pedagógicas desenvolvidas nesse trabalho.

A partir da música "Eu"8, ouvida e cantada pelas crianças, pude abordar questões referentes às variadas origens das quais somos constituídos, pois somos descendentes de nossos pais e avós que também possuem as origens mais diversas. Na sequência, trabalhamos com a canção "Gente tem sobrenome", explorandoa no sentido de destacar o que representam os sobrenomes, para que servem e como e por que surgiram. Em discussão com a turma, chegamos à conclusão de que os mesmos servem para nos identificar, para diferenciar uma pessoa da outra, principalmente quando possuem o mesmo nome, e, também, que eles podem nos ajudar a descobrir as origens das nossas famílias. Alguns alunos ainda contribuíram com informações importantes: "Tem alguns sobrenomes que têm origem nas profissôes", "Meu primo me contou que na época dos escravos os donos deles colocavam seus nomes como sobrenome dos escravos, usando no meio a palavra do, que mostrava que o escravo era daquela pessoa”. Para complementar o estudo, trouxe a seguinte informação que nos ajudaria a entender como sugiram os sobrenomes:

A vida era obviamente mais simples quando havia apenas dois de cada espécie. [...] À medida que as pessoas se multiplicavam, contudo, se tornou necessário distinguir uma da outra, surgiram nomes próprios. $\mathrm{E}$ quando estes não mais eram suficientes, várias formas de nomear foram adicionadas, mostrando ascendência, profissão, origem ou alguma outra característica que diferenciasse as diversas pessoas que viviam numa única comunidade ${ }^{10}$.

\footnotetext{
${ }^{8}$ Canção do CD "Canções Curiosas", de Paulo Tatit.

9 Canção do CD "Canção de Todas as Crianças", de Toquinho.

${ }^{10}$ Excerto de Dr. Harvey Minkoff. Adaptadado de Di Yiddishe Heim. Retirado do site: http://www.chabad.org.br/biblioteca/artigos/sobre_nomes/origem_nomes.html. Acesso em: 20 set. 2009.
} 
Em seguida, partimos para uma pesquisa realizada através de entrevista com os familiares sobre a origem dos sobrenomes da família do pai e da mãe, os países de origem de suas famílias e as histórias familiares que poderiam dar pistas importantes para o nosso estudo. Como defende Hickmann (1997, p. 57-58):

A história oral ou de vida, assim como entrevistas, podem ser valiosos instrumentais para se recorrer neste movimento de contextualizar o conhecimento escolar, em que a criança procura resgatar a sua história pessoal, da família e do seu povo, dando-se a conhecer.

A entrevista proposta foi um recurso muito válido no resgate das memórias familiares e o retorno dessa atividade foi surpreendente. A qualidade e riqueza dos achados das crianças fizeram com que pudéssemos ampliar bastante as discussões nos momentos em que estas partilharam suas descobertas, me motivando a propor um novo estudo, que contarei em seguida.

Transcrevo, aqui, alguns escritos dos alunos que mostram a riqueza dos seus achados a respeito das histórias da origem de suas famílias:

O meu tataravô veio para o Brasil porque lá [na Itália] a vida era muito difícil.

Meu avô veio para o Brasil ainda menino. Seus pais estavam fugindo de Hitler. Por que estava fazendo a $2^{\mathrm{a}}$ Guerra Mundial. E queria dominar o mundo.

Minha tataravó nasceu na Lei do Ventre Livre. Era de origem africana.

A família do meu pai tem um pouco de sangue árabe.

A minha mãe me contou que o bisavô dela foi escravo. Os tataravôs de meu pai vieram da Itália, trabalhavam na agricultura e criavam gado.

O meu tataravô era mascate em Portugal. Veio ao Brasil vender suas mercadorias e aqui ficou.

O pai da minha mãe era descendente de índios e minha avó é descendente de alemães, sendo que seus tataravós foram as pessoas da família que vieram para o Brasil.

Meu bisavô veio para o Brasil fugindo da Guerra do Paraguai e fez uma família. 
Procurei dar voz às crianças, oportunizando espaços em que elas pudessem partilhar suas histórias familiares recémdescobertas, gerando discussões muito interessantes, como, por exemplo, sobre a Lei do Ventre Livre, trazida por um aluno negro e a $2^{\text {a }}$ Guerra Mundial, trazida por uma aluna branca de ascendência alemã. Aproveitei também, partindo dessa atividade, para fazer uma exploração cartográfica, localizando com os alunos, no mapa-múndi da sala de aula, os países de origem de todos eles.

Percebendo o interesse dos alunos e a vontade de saber mais sobre os assuntos que estavam sendo trabalhados, propus um estudo mais aprofundado dos principais povos de origem da turma. Elegemos para o estudo os povos: portugueses, espanhóis, africanos, italianos, indígenas e alemães. Dividimos a turma em seis grupos e estes se organizaram no sentido de pensarem o que já sabiam sobre esses povos e o que desejavam descobrir/aprender. Partindo das principais curiosidades das crianças, iniciamos as pesquisas utilizando como material para consulta livros retirados na biblioteca da escola, materiais trazidos de casa pelas crianças e pela professora e buscas na internet. Após algumas aulas destinadas ao trabalho em grupo para a pesquisa e também para a preparação de material visual, fizemos um seminário quando cada grupo apresentou suas descobertas. Segundo Callai e Callai (1998),

ao defender suas idéias, os alunos avançam na compreensão do que estão estudando, aprendem a falar em público, aprendem a ouvir questionamentos e dúvidas e a tentar respondê-los. Ao escrever, formalizam o registro que está sendo discutido e escrevem um texto que resulta de um trabalho concreto: devem pensar no que aconteceu para demonstrar como entenderam e como conseguem se expressar. (p. 64).

\section{Encerrando o projeto}

Todo o projeto deve finalizar com uma síntese que corresponde ao momento de organização dos dados, da avaliação por parte dos estudantes e professores a partir do que sabiam e do 
que descobriram durante o mesmo. Esta é a etapa de "divulgação dos achados para interlocutores reais $[\ldots]$, sob diferentes formas [...]. É a passagem da pedagogia do discurso para a pedagogia da ação" (XAVIER, 2003, p. 23).

Assim, para finalizar nosso projeto, fizemos dois movimentos diferenciados. O primeiro consistiu na realização de um seminário, já comentado anteriormente, através do qual as crianças apresentaram aos colegas as pesquisas realizadas em grupos sobre os países e povos de origem da turma. Para tanto, utilizaram cartazes com imagens e informações obtidas na pesquisa, confeccionaram bandeiras das regiões, trouxeram comidas típicas e realizou-se também uma apresentação musical de flauta com músicas da cultura alemã.

Um segundo movimento foi a montagem individual de um livro referente ao projeto "Descobrindo a beleza das nossas origens”. O mesmo foi composto por uma capa ornamentada pelas crianças e um sumário contendo todas as atividades realizadas durante o projeto. Além disso, todos os textos lidos e materiais produzidos foram reunidos para formar o livro. Dentre esses materiais, destaco a autobiografia com foto, o autorretrato a partir do poema "Na minha pele", o acróstico com as letras do nome, o quadro de origens, a árvore da família, os excertos das produções dos alunos sobre: "O que sabemos sobre os índios?” e "O que aprendemos/descobrimos sobre os povos indígenas?", a entrevista com os pais sobre as origens dos sobrenomes e histórias familiares, o mapa com a localização dos países de sua origem e um texto sobre os aprendizados construídos com as atividades ligadas ao projeto.

Este último consistia num texto em que as crianças deveriam contar um pouco o que aprenderam/descobriram com o projeto. Também, deveriam falar do que mais gostaram e do que não gostaram, tecendo alguns outros comentários que julgassem importantes. Esse teve como objetivo ver de que forma as crianças avaliariam o projeto. Destaco a seguir os escritos de algumas crianças: 
Eu aprendi que a gente não pode ser racista com as outras pessoas. Gostei muito dos trabalhos em grupo e dos outros também. No que aprendi sobre a escravidão no Brasil não gostei nem um pouco da maneira como os escravos eram tratados e do jeito como eles vinham para o Brasil nos navios negreiros. E eu aprendi um pouco a cultura da Espanha.

No projeto, eu aprendi muita coisa. Eu gostei do trabalho da árvore genealógica porque tem o nome da minha família e descobri muitas coisas. Eu não gostei que me deu muito trabalho a entrevista com os pais e avós sobre as origens dos sobrenomes e das famílias porque tinha que ligar para perguntar as origens [...]. Mas dos outros trabalhos gostei muito e aprendi muitas coisas e quero aprender mais para eu ficar inteligente e saber tudo.

Eu gostei da origem dos nossos nomes porque eu descobri que o meu sobrenome veio de Portugal. O filme que eu assiti do índio eu aprendi que quando uma pessoa pobre estiver dormindo no banco da praça não quer dizer que tenha que fazer mal. $\mathrm{O}$ assunto que eu mais gosto é pesquisar sobre os países, e no grupo eu conheço melhor os colegas. O que eu gostaria de aprender mais é sobre a vida do índio.

$\mathrm{Eu}$ aprendi que cada país tem a sua origem. Tem gente que tem origem italiana e não come massa. Também no dia que a princesa Isabel assinou a Lei do Ventre Livre ${ }^{11}$ as pessoas que nasciam não eram mais escravos, mas os que já eram continuaram sendo e que cada pessoa tem 1, 2 ou 3 origens. Eu descobri que nenhuma pessoa é diferente, todas são iguais e nenhuma raça é mais que a outra. Do que eu mais gostei no projeto foi pintar os países aonde a gente mora e aonde tem origens, e eu não gostei daquilo... o que sabemos sobre os índios e o que eu queria dizer era que eu gostei de tudo.

Olhando para todas essas aprendizagens e as muitas outras explicitadas pelos alunos durante as aulas, me parece que os objetivos deste trabalho foram alcançados. Os alunos mostraram-se engajados e conscientes daquilo que estavam aprendendo nos diferentes momentos do projeto. Percebi a grande dificuldade que a turma ainda apresentava em desenvolver trabalhos de pesquisa em grupos. Mesmo assim, avalio como positivo os resultados desse trabalho, pois, apesar de ter gerado alguns conflitos, também proporcionou um espaço de oralidade, de

11 Esta lei foi aprovada pelo Parlamento do Império, em 1871. 
troca de ideias, de posicionar-se em relação aos colegas, de aprendizado de trabalho coletivo, de síntese e seleção de ideias.

\section{Últimos apontamentos}

Neste artigo, foram apresentadas apenas algumas formas, de um mundo de possibilidades, pelas quais a multiplicidade, a pluralidade e as diferenças podem ser abordadas. Não podemos esquecer que trabalhar com as diferenças, não é trabalhar somente com um universo macro, mas, principalmente, com as multiplicidades existentes dentro da própria sala de aula. Esse movimento se faz necessário tanto pela urgência de que nossas crianças e jovens aprendam a ter uma relação mais sensível consigo e com a sociedade, como também por adequação às novas legislações a respeito da inclusão no currículo oficial da temática "História e Cultura Afro-Brasileira e Indígena". A aprovação destas Leis Federais (Lei 10.639 de 09/01/2003 e Lei No 11.645 de 10/03/2008) foi possível a partir da organização e luta dos movimentos sociais visando a reconhecer e valorizar a história, a cultura e as identidades desses povos. Tal política de ação afirmativa busca combater o racismo e a discriminação propondo:

[...] a divulgação e a produção de conhecimentos, a formação de atitudes, posturas e valores que eduquem cidadáos orgulhosos de seu pertencimento etnicorracial - descendentes de africanos, povos indígenas, descendentes de europeus, de asiáticos - para interagirem na construção de uma nação democrática, em que todos igualmente, tenham seus direitos garantidos e sua identidade valorizada. (BRASIL, 2004, p. 2).

Se em alguma medida, através da prática pedagógica, conseguirmos produzir alguns deslocamentos, perturbar certezas, provocar rupturas, possibilitar que outras narrativas, outros modos de pensar, sejam produzidos e nos produzam enquanto sujeitos, a escola estará cumprindo com sua tarefa, educando as crianças e jovens para relações mais sensíveis. Pois é no cotidiano, nas ações aparentemente banais que a escola converte diferenças em desigualdades. E é também nesses espaços que as crianças podem produzir suas respostas e resistências. 


\section{Referências}

BRASIL. Diretrizes Curriculares Nacionais para a Educação das Relações Étnico-Raciais e para o Ensino de História e Cultura Afro-Brasileira e Africana. Conselho Nacional de Educação, 10 de março de 2004.

BONIN, Iara Tatiana. E por falar em povos indigenas... quais narrativas contam em práticas pedagógicas?, 2007. Tese (Doutorado em Educação). Universidade Federal do Rio Grande do Sul. Porto Alegre, 2007.

CALLAI, Helena Copetti. CALLAI, Jaeme Luiz. Grupo, espaço e tempo nas Séries Iniciais. In: CASTROGIOVANNI, Carlos Antonio (org.) [et. al.] . Geografia em sala de aula - práticas e reflexões. Porto Alegre: Associação dos Geógrafos Brasileiros - Seção Porto Alegre, 1998.

CALLAI, Jaeme Luiz. História de Vida, História de Familia nas Séries Iniciais, uma Introdução à Forma de Pensar Histórica. Espaço da Escola. RS: UNIJUI, Ano 4, n 15, p. 37-43 jan/mar., 1995.

CANEN, Ana. Sentidos e dilemas do multiculturalismo: desafios curriculares para o novo milênio. In: LOPES, A. C., MACEDO, E. (Org). Currículo: debates contemporâneos. São Paulo: Cortez, p. 174-195, 2002.

FREIRE, Madalena. O que é um grupo? In: FREIRE, Madalena (Org.). Grupo, Individuo, saber e parceria: malhas do conhecimento. 2 ed. São Paulo: Espaço Pedagógico, 1997.

GERALDI, João Wanderley. Escrita, uso da escrita e avaliação. In: GERALDI, João Wanderley (Org.). O texto na sala de aula. São Paulo: Ática, 1997.

GRUPIONI, Denise Fajardo. Os Índios da América Central e a Construção de uma Cultura da Tolerância. In: GRUPIONI, Denise Fajardo. Povos Indígenas e Tolerância São Paulo: Edusp/Unesco, 2001.

HERNÁNDEZ, Fernando; VENTURA, Montserrat. Os projetos de trabalho: uma forma de organizar os conhecimentos escolares. In: $A$ organização do currículo por projetos de trabalho: o conhecimento é um caleidoscópio. Porto Alegre: Artes Médicas, 1998.

HICKMANN, Roseli Inês. As ciências sociais no currículo vivido: sobre o olhar da cultura e da memória. In: XAVIER, Maria Luisa Merino. DALLA ZEN, Maria Isabel Habckost. O ensino nas séries iniciais: das concepções teóricas às metodologias. Porto Alegre: Mediação, 1997. 
HICKMANN, Roseli Inês. Ciências sociais no contexto escolar: para além do espaço e do tempo. In: HICKMANN, Roseli Inês (org.). Estudos Sociais: outros saberes e outros sabores. Porto Alegre: Mediação, 2002.

JOLIBERT, Josette (Coord.). Formando crianças leitoras. Traduzido por Bruno C. Magne. Porto Alegre: Artes Médicas, 1994.

LOPES, Luiz Paulo da Moita. Identidades fragmentadas: a construção discursiva de raça, gênero e sexualidade em sala de aula. Campinas: Mercado das Letras, 2002.

SANTOMÉ, Jurjo Torres. As culturas negadas e silenciadas no currículo. In: SILVA, Tomaz Tadeu da (Org.). Alienígenas na Sala de Aula - Uma introdução aos estudos culturais em educação. Petrópolis, Vozes, 1995.

SILVA, Aracy Lopes da. GRUPIONI, Luís Donisete Benzi (orgs.). A temática indigena na escola: novos subsídios para professores de $1^{\circ} \mathrm{e}$ $2^{\circ}$ graus. Brasília, MEC/Mari/Unesco, 4 ed. 2004.

SILVA, Tomaz Tadeu da. Currículo e Identidade Social: Territórios Contestados. In: SILVA, Tomaz Tadeu da (Org.). Alienígenas na Sala de Aula - Uma introdução aos estudos culturais em educação. Petrópolis: Vozes, 1995.

SILVA, Tomaz Tadeu da. Documentos de identidade: uma introdução às teorias do currículo. Belo Horizonte: Autêntica, 2004.

XAVIER, Maria Luisa Merino. Introduzindo a questão do planejamento: globalização, interdisciplinaridade e integração curricular. In: XAVIER, Maria Luisa M. DALLA ZEN, Maria Isabel H. (Orgs.). Planejamento em Destaque: Análises Menos Convencionais. Porto Alegre: Mediação, 2003. 